RESEARCH REPORT

\title{
Nociceptin and its receptor in rat dorsal root ganglion neurons in neuropathic and inflammatory pain models: implications on pain processing
}

\author{
Yong Chen and Claudia Sommer \\ Department of Neurology, Julius-Maximilians-University, Würzburg, Germany
}

\begin{abstract}
Nociceptin (NC), by activating its receptor, the opioid receptor-like 1 (ORL1) receptor, exerts an effect on a number of functions in the nervous system including locomotion, learning and memory, and processing of pain signals. Data on the expression of $\mathrm{NC}$ and ORL1 receptor in dorsal root ganglion (DRG) neurons and on its modulation after nerve injury and inflammation are controversial. We therefore sought to investigate the immunoreactivity (IR) of NC and ORL1 receptor in DRG neurons in two pain models, a pure neuropathic pain model, namely partial sciatic nerve transection (PST), and an inflammatory pain model, complete Freund's adjuvant (CFA) injection into the hindpaw. In intact DRG neurons, both NC and ORL1 receptor IR were present in mainly small- and mediumsized neurons, NC IR in 31\% and ORL1 receptor IR in 33\% of all neuronal profiles. Both NC and ORL1 receptor IR were upregulated 7 days after nerve injury (to 56 and 55\%) and inflammation (to 53 and 48\%), respectively. Activating transcription factor 3 (ATF3), a neuronal marker of nerve injury, was induced in DRG neurons 7 and 14 days after PST and 7 days after CFA injection. Double labeling with ATF3 revealed expression of NC and ORL1 receptor in intact as well as in injured primary afferent neurons. Thus, NC and the ORL1 receptor may be involved in the modulation of neuropathic and inflammatory pain at the level of the primary afferent neuron.
\end{abstract}

Key words: activating transcription factor 3, dorsal root ganglion, nociceptin, opioid receptor-like 1, pain

\section{Introduction}

Nociceptin (NC) (Meunier et al., 1995), otherwise known as orphanin FQ (Reinscheid et al., 1995), is an endogenous ligand for the opioid receptor-like 1 (ORL1) receptor. Although sharing sequence homology with classical opioid peptides, NC has a distinct pharmacological profile. Injections of NC into the

Address correspondence to: Yong Chen, PhD, Neurologische Klinik der Universität, Josef-Schneider-Str. 11, 97080 Würzburg, Germany. Tel: +49 931201 24621; Fax: +49 931201 23697; E-mail: chen_y@klinik.uni-wuerzburg.de central or peripheral nervous system of rats and mice change their responsiveness to painful stimuli. Both pro- and antinociceptive effects have been reported in a variety of animal models depending on the testing paradigm, animal species, doses, and route of administration (Calo' et al., 2000; Mogil and Pasternak, 2001; Heinricher, 2003). The diverse effects of NC are consistent with its supposed neuromodulatory function, exercised via the ORL1 receptor. The receptor is a $\mathrm{G}_{i} / \mathrm{G}_{0}$-protein-coupled receptor whose activation results in inhibition of voltage-gated $\mathrm{N}$-type calcium channels, suppression of adenylate cyclase, and activation of $\mathrm{K}^{+}$channels, which in turn inhibits release of 
neurotransmitters (Henderson and McKnight, 1997). $\mathrm{NC}$, acting through the ORL1 receptor, produces antinociception in several models of neuropathy and inflammation. For example, intrathecal injection of NC reduced and suppressed mechanical allodynia in rats with diabetes and traumatic nerve injury (Courteix et al., 2004), and it attenuated the thermal hyperalgesia in rats with sciatic nerve chronic constriction injury (CCI) (Yamamoto et al., 1997a). NC produced antihyperalgesic and antiallodynic effects in rats after photochemically induced peripheral nerve or spinal cord ischemic injury (Hao et al., 1998). NC applied intrathecally had antinociceptive effects in the rat and mouse formalin test (Yamamoto et al., 1997b; Nakano et al., 2000) and in carageenan-induced pain (Yamamoto et al., 1997c; Hao et al., 1998; Xu et al., 1999). These results imply that NC can suppress pain transmission at the spinal cord level under pathological conditions.

$\mathrm{NC}$ and its receptor are localized in various regions of the central nervous system, which are associated with nociception, such as the cerebral cortex, thalamus, periaqueductal gray, and the spinal cord dorsal horn. The ORL1 receptor has been detected in the lumbar dorsal horn and the dorsal root ganglia (DRG). A similar pattern of distribution exists for NC and its precursor prepronociceptin (ppNC) mRNA (Harrison and Grandy, 2000; Mogil and Pasternak, 2001). Using different techniques such as immunohistochemistry, radioimmunoassay, autoradiography, and reverse transcription-polymerase chain reaction, some investigators showed increases in NC immunoreactivity (IR) in the spinal cord after injection of carageenan into the hindpaw (Rosen et al., 2000) and ligation of the sciatic nerve (Gabriel et al., 2004); further, the ORL1 receptor protein and mRNA in the spinal cord were upregulated after injection of carageenan into the hindpaw (Jia et al., 1998) and in $\mathrm{CCl}$ of the sciatic nerve (Briscini et al., 2002). In DRG, NC (Pettersson et al., 2002) and ppNC mRNA (Mika et al., 2003) have been shown in small neurons in naïve rats. Others found little or no ppNC mRNA in naïve rat DRG neurons but marked induction after carageenan-elicited inflammation (Andoh et al., 1997; Itoh et al., 2001). Interestingly, ppNC mRNA did not change in rat DRG neurons after $\mathrm{CCl}$ (Briscini et al., 2002). Although only weak ORL1 receptor IR was found in relatively few medium-sized somata in rat lumbar DRG (Monteillet-Agius et al., 1998), ORL1 mRNA was detected in rat DRG and it was upregulated after $\mathrm{CCl}$ (Briscini et al., 2002; Pettersson et al., 2002; Mika et al., 2003).

Thus, in spite of considerable knowledge about the roles of NC and ORL1 receptor in nociception and their distributions at the spinal cord level, data on their expression in DRG neurons and its modulation after nerve injury and inflammation are controversial. We therefore used two different pain models, namely partial sciatic nerve transection (PST), a pure nerve injury neuropathic pain model (Lindenlaub and Sommer, 2000), and complete Freund's adjuvant (CFA) injection into the hindpaw, a well-established inflammatory pain model (Stein et al., 1988), to investigate the changes of both NC and ORL1 receptor IR in primary sensory neurons.

\section{Materials and Methods}

\section{Animals and procedures}

Male Sprague-Dawley rats (200-300 g; Charles River) were used in this study. Animals were housed on a 14:10 h light:dark cycle with standard rodent chow and water available ad libitum. All experiments were approved by the Bavarian state authorities and carried out in accordance with the European Communities Council Directive of 24 November 1986 (86/609/EEC) for the care and use of laboratory animals.

L4 DRGs from rats sacrificed 7 days $(n=4)$ and 14 days $(n=4)$ after PST were from a previous experiment (Lindenlaub and Sommer, 2000). Briefly, under barbiturate anesthesia, the sciatic nerve was exposed at midthigh level and a prolene 7/0 ligature was placed through the midpoint of the nerve just cranially to the branch running to the musculus biceps femoris. Half of the diameter of the nerve was transected in a ventrocranial direction up to the ligature and then the ligature was removed. Six rats received CFA injections. Under ether anesthesia, $50 \mu \mathrm{l}$ of CFA [Mycobacterium tuberculosis; Difco Laboratories; diluted $1: 1$ with phosphate-buffered saline (PBS), $2 \mathrm{mg} / \mathrm{ml}]$ was injected subcutaneously into the intraplantar surface of one hindpaw with a Hamilton syringe coupled to a 30-gauge needle. Rats were sacrificed 7 and 14 days after PST and 7 days after CFA injection. Following peripheral nerve lesions, there are well-documented events on the contralateral nonlesioned sides (Koltzenburg et al., 1999); accordingly, the contralateral DRG neurons of partial sciatic nerve-transected and CFA-injected rats were not used as controls. Four additional rats that received a sham operation, where the sciatic nerve was exposed but not ligated, were used as a control group for PST. Three additional rats that received intraplantar injection of normal saline were used as a control for CFA injection. In a preliminary analysis, morphometric data (see below) were not different between normal saline-injected and sham-operated control rats (data not shown), such that only data from the sham-operated control rats were used for further analysis. 


\section{Immunohistochemistry}

The ipsilateral L4 DRG were removed, mounted in Tissue Tek OTC (Dialec) embedding compound, quickly frozen in liquid nitrogen, and stored at $-80^{\circ} \mathrm{C}$. DRG were sectioned on a cryostat at a thickness of $10 \mu \mathrm{m}$. In each rat, six DRG serial sections were selected randomly [three sections on one slide for NC and activating transcription factor 3 (ATF3) double staining, and three for ORL1 receptor and ATF3 double staining]. Sections were thaw-mounted onto Superfrost Plus slides (R. Langenbrinck) and air-dried for $30 \mathrm{~min}$. Sections were postfixed for $10 \mathrm{~min}$ in acetone at $-20^{\circ} \mathrm{C}$ and blocked with $10 \%$ bovine serum albumin/PBS for $30 \mathrm{~min}$. The following antibodies were used for immunofluorescence: rabbit antinociceptin antibody (AB; 1:800; Chemicon), polyclonal goat anti-KOR3 (otherwise known as polyclonal goat anti-ORL1; 1 : 250; Santa Cruz Biotechnology), polyclonal sheep anti-ATF3 (1: 100; Biogenesis). Sections were incubated at $4^{\circ} \mathrm{C}$ for $24 \mathrm{~h}$, washed three times for $10 \mathrm{~min}$ in PBS, and incubated for $2 \mathrm{~h}$ in a Cy3conjugated or Cy2-conjugated secondary $A B(1: 100$; Dianova). After immunostaining, sections were viewed and digitized at a magnification of $\times 400$ with a Zeiss Axiophot 2 microscope (Zeiss) and the relevant filter blocks (for Cy3, 546 nm and for Cy2, 450$490 \mathrm{~nm}$ ) and quantitatively analyzed by Image Pro Plus software (version 4.0; Media Cybernetics). The density threshold for positive IR was determined by averaging two or three cell bodies in each section that were judged to be minimally positive. All neurons for which the mean density exceeded the threshold were counted as positive, and the positive cells were expressed as the percentage of the total of counted DRG neurons [\% = (positive cells/total counted cells] $\times 100)$. The area of the NC and ORL1 receptor IR neuronal profiles was measured and displayed as size frequency distributions. The number of neuronal profiles labeled for both ATF3 and NC or ORL1 receptor, relative to the total number of NC- or ORL1-receptorpositive profiles, was obtained from double-labeled sections. To distinguish cell-size-specific changes, we characterized the DRG neurons as small $\left(<600 \mu \mathrm{m}^{2}\right)$, medium $\left(600-1,200 \mu \mathrm{m}^{2}\right)$ and large $\left(>1,200 \mu \mathrm{m}^{2}\right)$, according to their cross-sectional area (Fukuoka et al., 2001). Omission of the primary $A B$ and preabsorption with excess antigenic peptide abolished the specific signal of primary $A B$ (data not shown).

\section{Statistical analysis}

Results are presented as mean \pm SEM. Data were tested for statistical significance using unpaired $t$ test or ANOVA with post hoc comparison using Tukey test (SPSS 10.0). Significance was assumed with $p$ values of less than 0.05 .

\section{Results}

$N C$ and ORL1 receptor IR is increased in DRG neurons after PST and CFA

In DRG from sham-operated rats (controls), 31\% of neurons displayed IR for NC and 33\% for ORL1 receptor (Figs. $1 \mathrm{~A}$ and $1 \mathrm{~B}$ ). NC and ORL1 receptor IR were present in neurons of all sizes but predominantly in small- and medium-sized neurons (Figs. $1 \mathrm{E}$ and $1 \mathrm{~F}$; Fig. 3A; Fig. 4A). NC immunostaining caused intense somal IR with heterogeneously stained cytoplasm; ORL1 receptor IR was additionally present in nuclei. Seven days after PST or CFA injection, there was a significant increase in IR in the ipsilateral DRG: 56 and $55 \%$ neurons were positively labeled for $N C$ and ORL1 receptor after PST (Figs. $1 \mathrm{~A}$ and 1B; Fig. 3D; Fig. 4D; $p<0.01$ compared with controls) and 53 and 48\% after CFA injection (Figs. 2A and 2B; Fig. 3G; Fig. 4G; $p<0.01$ compared with controls). In addition, there was also a marked increase in NC and ORL1 receptor IR at day 14 after PST (Figs. $1 \mathrm{~A}$ and $1 \mathrm{~B} ; \mathrm{p}<0.01$ compared with controls). After both PST and CFA injection at 7 days, the number of smallsized DRG neurons with areas of $200-400 \mu \mathrm{m}^{2}$ with $\mathrm{NC}$ and ORL1 receptor IR was reduced $(p<0.01$ and $p<0.05$ compared with controls). In contrast, there was a trend toward an increase in NC and ORL1 receptor IR in large-sized $\left(>1,200 \mu \mathrm{m}^{2}\right)$ neurons (Figs. 1E and 1F; Figs. 2E and 2F; Figs. 3D and 3G; Figs. 4D and 4G).

\section{Presence of NC and ORL1 receptor IR in injured neurons}

ATF3 was used as a marker for injured neurons (Tsujino et al., 2000). None or very few neurons with ATF3 IR were found in DRG of sham-operated rats (Figs. 1A and 1B; Figs. 2A and 1B; Fig. 3B; Fig. 4B). Seven and 14 days after PST, 30-37\% of neurons displayed ATF3 IR (Figs. $1 \mathrm{~A}$ and $1 \mathrm{~B}$; Figs. 3E and $3 \mathrm{H}$ ), and 7 days after CFA injection, 23-24\% of neurons displayed ATF3 IR (Figs. 2A and 2B; Figs. 4E and 4H). In neurons from control DRG, there was no colocalization of NC and ORL1 with ATF3 (Figs. 1C and 1D; Figs. 2C and 2D; Fig. 3C; Fig. 4C). Both NC and ORL1 receptor were coexpressed with ATF3 7 days after PST (39 and 27\%, respectively; Figs. 1C and 1D; Fig. 3F; Fig. 4F) and 7 days after CFA injection (30 and 17\%, respectively; Figs. 2C and 2D; Fig. 31; Fig. 4I). Colocalization of NC and ORL1 receptor with ATF3 was still present 14 days after PST (Figs. 1C and 1D).

\section{Discussion}

The main findings in this study are an increase in $\mathrm{NC}$ and ORL1 receptor IR in L4 DRG neurons 7 days 
A
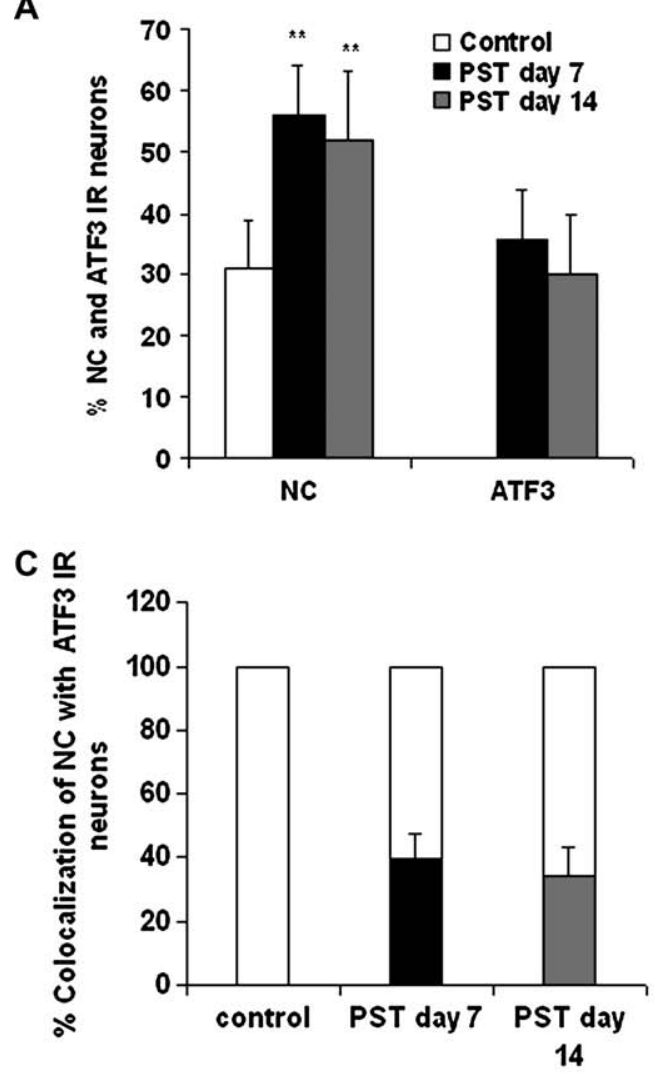

E

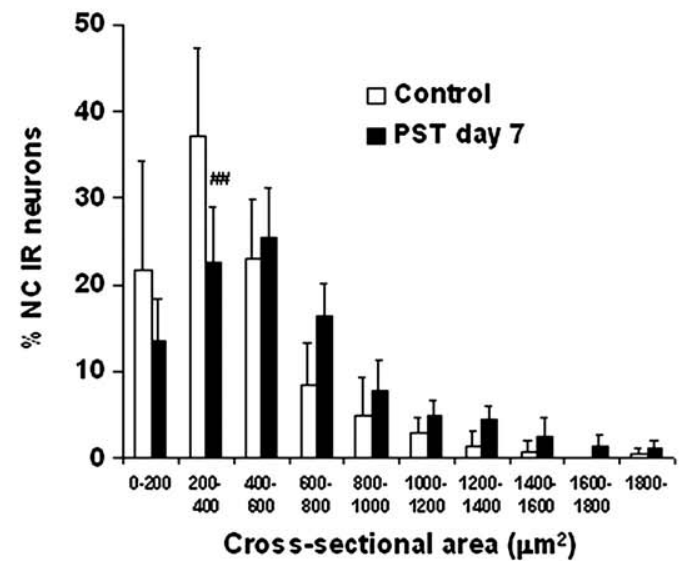

B
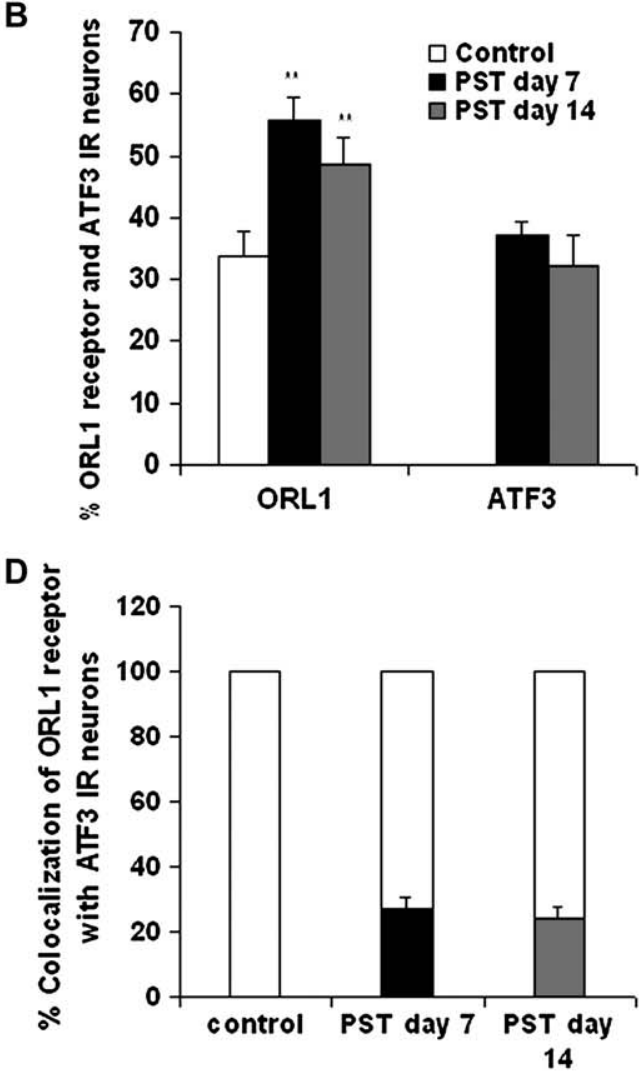

$\mathbf{F}$

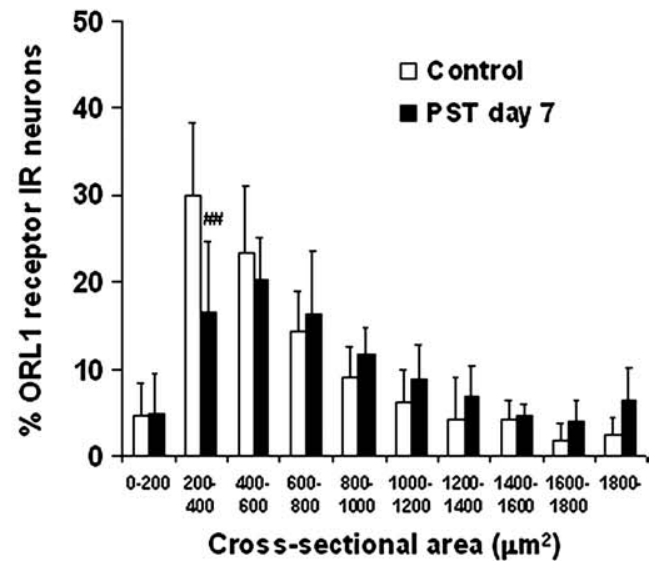

Figure 1. Percentage of nociceptin (NC) (A) and ORL1 receptor immunoreactivity (IR) (B) in ipsilateral L4 dorsal root ganglion neurons in controls, 7 days, and 14 days after partial sciatic nerve transection (PST). Percentage of activating transcription factor 3 (ATF3) IR neurons in the same sections as visualized after double staining. NC (A) and ORL1 receptor IR (B) are increased 7 days after PST (**p $<0.01$ compared with controls, unpaired $t$ test). Colocalization of NC (C) or ORL1 (D) with ATF3. Seven and 14 days after PST, NC and ORL1 receptor IR were colocalized with ATF3, in 39 and $27 \%$ of neurons, respectively. Size frequency histograms illustrating the distribution of cross-sectional areas of NC (E) and ORL1 receptor IR (F). NC and ORL1 receptor IR were predominantly localized in small- to medium-sized neurons. Note a size frequency shift away from small-sized $\left(200-400 \mu \mathrm{m}^{2}\right)$ neurons 7 days after PST (\#\# $\mathrm{p}<0.01$ compared with controls, ANOVA followed by Tukey test). $n=4$ for each group.

after induction of a partial sciatic nerve injury (PST) or hindpaw inflammation (CFA). ATF3 as an indicator of injured neurons was induced in one-fourth to onethird of DRG neurons in both models. NC and ORL1 receptor were present in injured and uninjured neurons in both models.

The increase of NC IR after CFA injection is consistent with previous work, showing carageenan-induced 
A
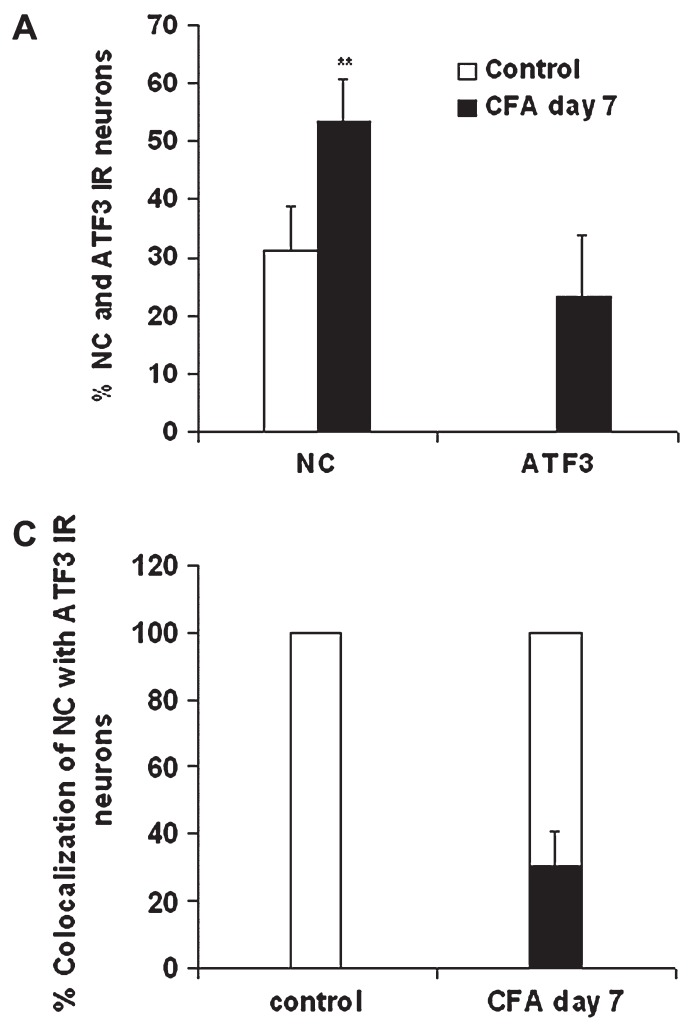

E

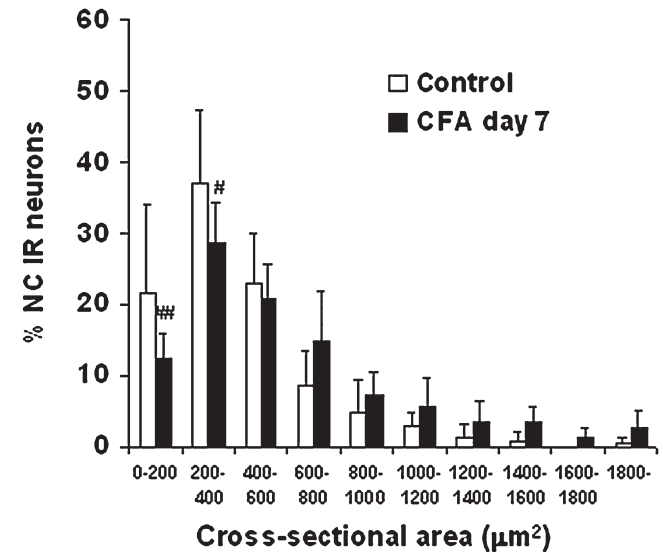

B

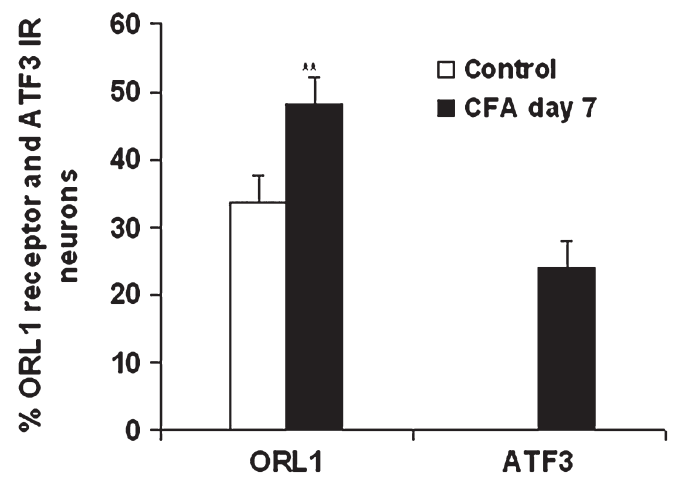

D

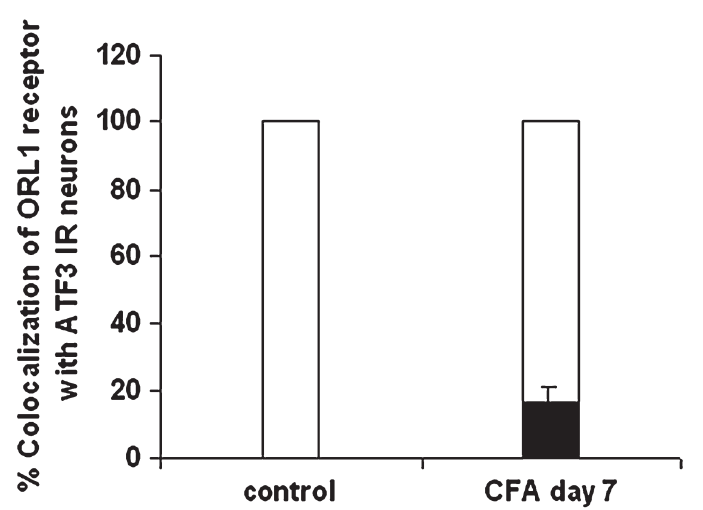

$\mathbf{F}$

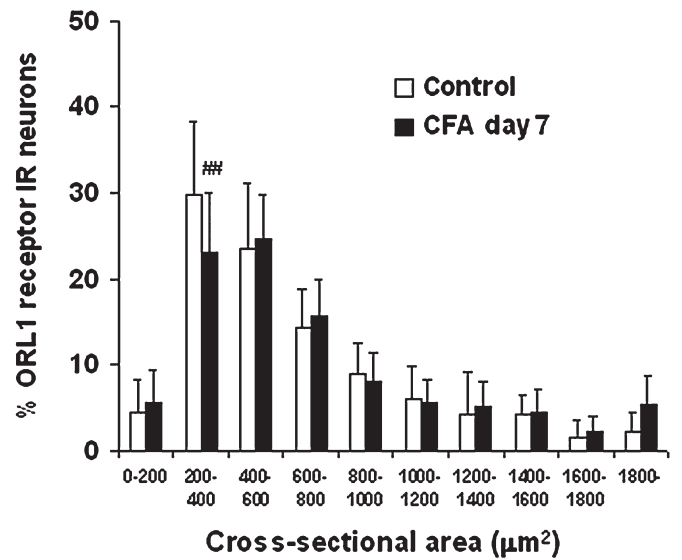

Figure 2. Percentage of nociceptin (NC) (A) and ORL1 receptor immunoreactivity (IR) (B) in ipsilateral L4 dorsal root ganglion neurons in controls $(n=4)$ and 7 days after complete Freund's adjuvant (CFA) injection $(n=6)$. Percentage of activating transcription factor 3 (ATF3) IR neurons in the same sections as visualized after double staining. NC (A) and ORL1 receptor IR (B) are increased 7 days after CFA (**p $<0.01$ compared with control, unpaired $t$ test). Colocalization of NC (C) or ORL1 (D) with ATF3. Seven days after CFA, NC and ORL1 receptor IR were colocalized with ATF3, in 30 and $17 \%$ neurons, respectively. Size frequency histograms illustrating the distribution of cross-sectional areas of NC (E) and ORL1 receptor IR (F). NC and ORL1 receptor IR were predominantly localized in small- to medium-sized neurons. Note a size frequency shift away from small-sized $\left(<400 \mu \mathrm{m}^{2}\right)$ neurons 7 days after CFA injection ( $\#<0.05$ and $\# \#<0.01$ compared with controls, ANOVA followed by Tukey test).

expression of ppNC mRNA (Andoh et al., 1997). Although ppNC mRNA did not change in L5 and L6 DRG neurons after $\mathrm{CCl}$ in a previous study (Briscini et al., 2002), we found increased NC IR in DRG neurons after PST. This discrepancy may be related to the difference in neuropathic pain models but more likely to the investigation of mRNA vs. protein. It is conceivable that the increase in NC protein after nerve injury is due to posttranscriptional regulation. After PST and CFA injection, ORL1 receptor IR was increased in DRG neurons. This is in agreement with previous studies, showing that ORL1 mRNA is present in rat DRG and upregulated after $\mathrm{CCl}$ (Briscini et al., 2002; Pettersson et al., 2002; Mika et al., 2003). 


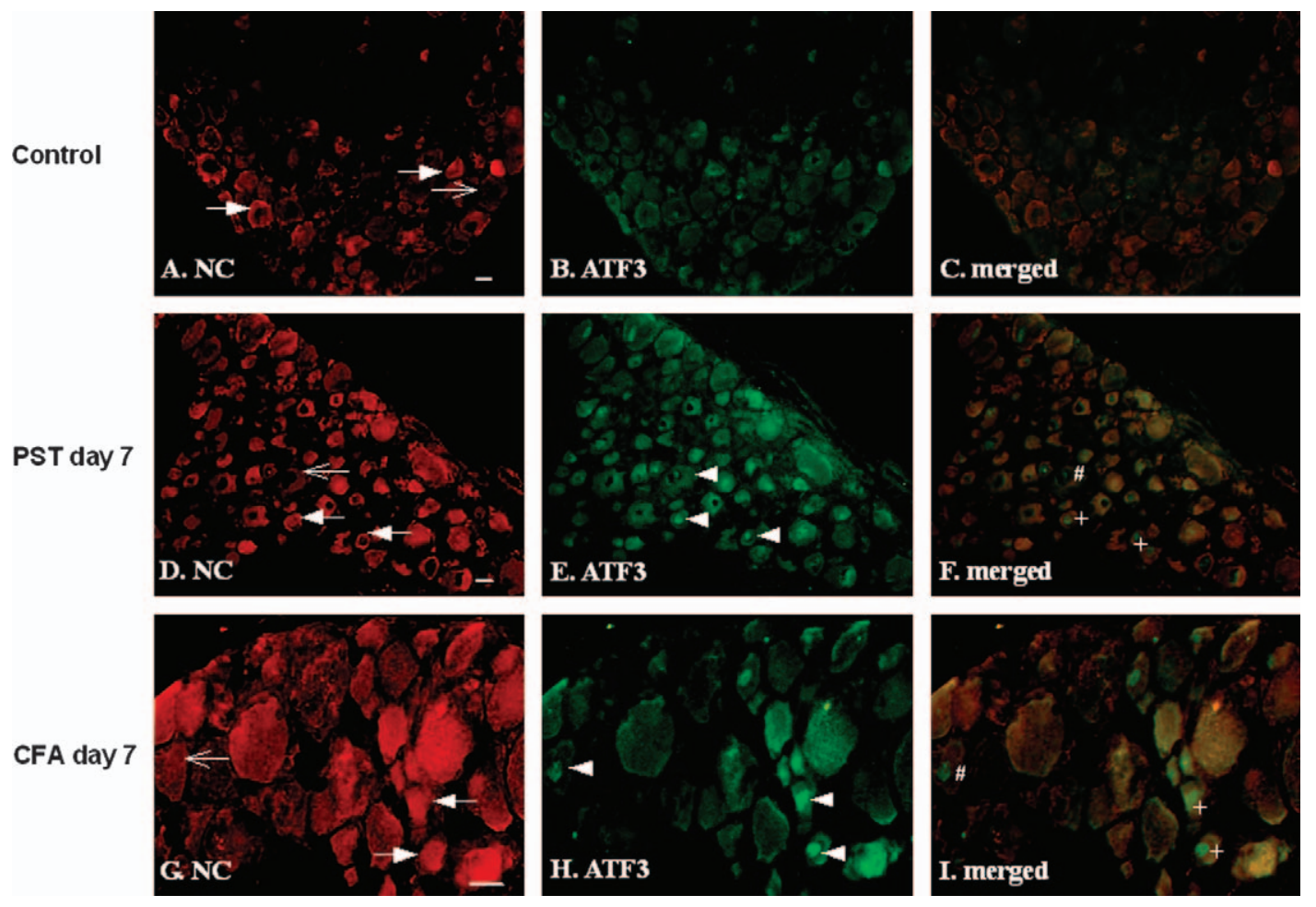

Figure 3. Photomicrographs showing nociceptin (NC) and activating transcription factor 3 (ATF3) immunoreactivity (IR) in L4 dorsal root ganglion from controls (A-C), 7 days after partial sciatic nerve transection (D-F) and complete Freund's adjuvant injection (G-I). Arrows, open arrows, and arrowheads for NC-positive, NC-negative, and ATF3-positive profiles, respectively. C, F, and I: merged images show neuronal profiles with double labeling of NC with ATF3 (' + ' and '\#' for colocalization positive and colocalization negative, respectively). Scale bars in A and D for A-F: $20 \mu \mathrm{m}$; in G for G-I: $40 \mu \mathrm{m}$.

Additionally, the increases in NC and ORL1 receptor IR after PST and CFA injection are in line with previous reports, showing that peripheral nerve injury and inflammation induce upregulation of the synthesis of other opioid peptides and receptors at the spinal cord level (Dubner and Ruda, 1992; MacArthur et al., 1999; Truong et al., 2003; Zöllner et al., 2003). Considering that both pro- and anti-nociceptive effects of NC at the spinal cord level have been reported (Calo' et al., 2000; Mogil and Pasternak, 2001; Heinricher, 2003), it remains to be determined whether the activation of the NC/ORL1 receptor system after PST and CFA injection is associated with hyperalgesia or with the suppression of nociceptive hypersensitivity. The distribution of NC generally matched that of ORL1 receptor in control, PST-, and CFA-treated DRG neurons. After PST and CFA injection, a larger percentage of large DRG neurons, which probably correspond to low-threshold myelinated mechanoreceptors, expressed NC and ORL1 receptor. Thus, a phenotypic change occurred following neuropathy or inflammation, namely a decrease in some classes of small-sized DRG neurons for NC and ORL1 receptor $I R$, and there was a trend toward an increase in large-sized neurons.
The role of NC in afferent neurons is as yet incompletely understood. The majority of functional studies using behavioral and electrophysiological studies have shown that at the spinal level, NC produces antinociception through pre- and postsynaptic mechanisms. Just like $\mu, \delta$, and $\kappa$ receptors, activation of ORL1 receptor by NC is associated with inhibition of cyclic adenosine monophosphate formation (via $\mathrm{G}_{\mathrm{i}} /$ $\mathrm{G}_{\mathrm{o}}$-mediated intracellular signaling), closure of voltage-gated $\mathrm{N}$-type calcium channels, enhancement of an inwardly rectifying potassium conductance, and, ultimately, reduction of neuronal excitability (Hawes et al., 2000). NC release into the spinal cord can reduce dorsal horn reflexes and thus attenuate neurogenic inflammation (Dong et al., 2002). The inhibitory actions of NC are increased after inflammation, which has been attributed to an increase in spinal ORL1 receptor density (Carpenter et al., 2000). The increase in NC in DRG neurons and thus the possibly enhanced spinal NC release from afferent neurons may be an additional factor in this regulatory circuit. At the DRG level, electrophysiological studies predicted an excitatory effect of NC (Abdulla and Smith, 1998). This dichotomy between an excitatory peripheral effect and an inhibitory central effect is known for 

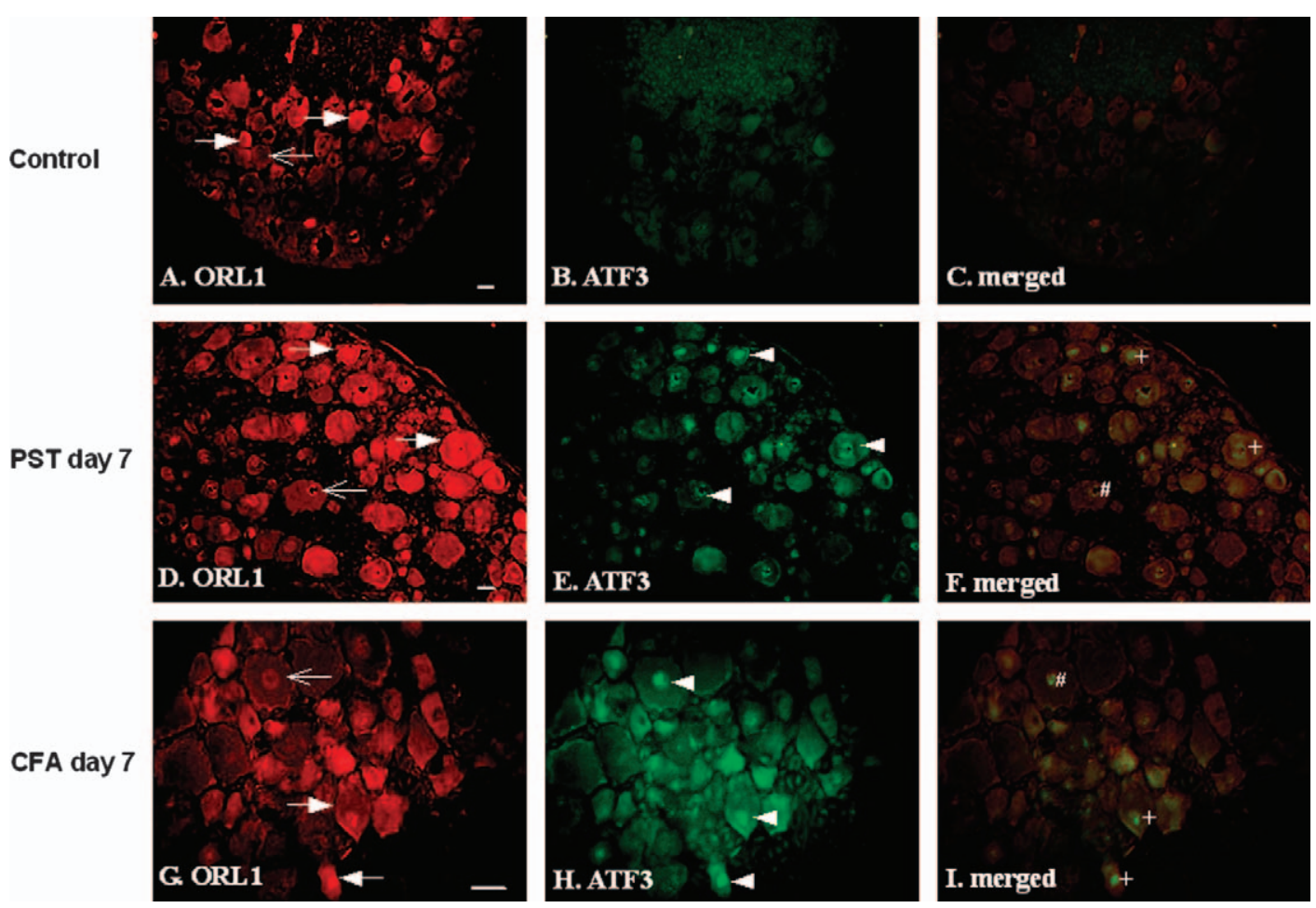

Figure 4. Photomicrographs showing ORL1 receptor and ATF3 immunoreactivity (IR) in L4 dorsal root ganglion from controls (A-C), 7 days after partial sciatic nerve transection (D-F), and complete Freund's adjuvant injection (G-I). Arrows, open arrows, and arrowheads for ORL1 receptor-positive, ORL1 receptor-negative, and ATF3-positive profiles, respectively. C, F, and I: merged images show neuronal profiles with double labeling of ORL1 receptor with ATF3 ('+' and '\#' for colocalization positive and colocalization negative, respectively). Scale bars in A and D for A-F: $20 \mu \mathrm{m}$; in $\mathrm{G}$ for $\mathrm{G}-\mathrm{I}$ : $40 \mu \mathrm{m}$.

other molecules such as serotonin that is regulated by nerve injury or inflammation (Sommer, 2004). Axonal transport of ORL1 receptor from the DRG to the periphery and insertion into axonal membranes is likely because inflammation is known to enhance transport and accumulation of opioid receptors on the peripheral terminals of sensory neurons (Janson and Stein, 2003). Production and release of NC from nonneuronal cells like neutrophils and blood lymphocytes (Arjomand et al., 2002; Fiset et al., 2003) may be increased in peripheral tissues in inflammation and act on afferent fibers. Whether this assumed action of NC on ORL1 receptor on peripheral nerve is inhibitory or excitatory will have to be examined.

Antinociceptive actions of NC are mediated by the ORL1 receptor because they are absent in ORL1 receptor knockout mice (Henderson and McKnight, 1997; Calo' et al., 2000; Mogil and Pasternak, 2001). Furthermore, [Nphe1]NC(1-13) NH2, a pure and selective antagonist of the ORL1 receptor, antagonized the spinal inhibitory effect of NC (Xu et al., 2002). These results implied that NC produces analgesic effects in spinal cord via its receptor, namely ORL1. However, Bertorelli and colleagues suggested that the presence of ORL1 receptor is not crucial for the development of either acute or CCl-induced neuropathic nociceptive responses (Bertorelli et al., 2002), such that the significance of signaling via the ORL1 receptor in neuropathic pain is as yet unclear.

The induction of ATF3 is part of the cellular response after nerve injury. Following transection of a peripheral nerve, ATF3 mRNA is immediately induced in virtually all DRG neurons. The ATF3 mRNA signal was also shown in some DRG neurons 3 days after intraplantar injection of formalin but not on day 3 after intraplantar injection of CFA (Tsujino et al., 2000). ATF3, a member of the ATF cyclic AMP response element-binding protein (CREB) family of transcription factors, is a stress-induced gene, its mRNA level greatly increases on the exposure of cells to stress signals. In cultured cells, the signals include serum factors, cytokines, genotoxic agents, cell-deathinducing agents, and the adenoviral protein E1A. In animal models, the signals include ischemia, ischemia coupled with reperfusion, wounding, axotomy, toxicity, seizure, and chemicals such as alcohol, carbon tetrachloride, or acetaminophen (Hai and Hartman, 2001). In this study, 23-24\% of DRG neurons showed ATF3 IR 7 days after CFA injection. This apparent discrepancy with previous work (Tsujino et al., 2000) 
may be due to the difference in time-points, methods, and sensitivity of detection. CFA leads to a significant activation of c-Jun $\mathrm{N}$-terminal kinase (JNK) in DRG neurons at 60-120 min (Doya et al., 2005). Although it is still uncertain whether this activation may be responsible for the effects we saw at 7 days after CFA injection, it is conceivable that ATF3 expression may be induced via JNK in the CFA model when considering that ATF3 was originally identified as a stress-activated factor that can be induced by the JNK pathway (Hai and Hartman, 2001).

Given that a subpopulation of NC and ORL1 receptor IR neurons were injured in the two models used, the increase in IR for both the ligand and the receptor has to be attributed to injured as well as uninjured neurons. This is another example of a phenotype change in neighboring uninjured neurons in a partially injured nerve, as previously shown, for example, for brain-derived neurotrophic factor and tumor necrosis factor-alpha (Fukuoka et al., 2001; Schäfers et al., 2003). Assuming that the ATF3 IR neurons are injured and thus not functional, the presence of NC and its receptor in the uninjured population should be functionally more important and may have a role in processing of nociceptive information.

In conclusion, our data showed that both NC and ORL1 receptor IR are present in naïve DRG neurons; further, they are increased after peripheral nerve injury and inflammation. This study suggests that the NC/ORL1 receptor signaling pathway is active in the processing of pain information within DRG neurons, thus modulating afferent transmission already at the level of the first afferent neuron.

\section{Acknowledgements}

Barbara Dekant and Lydia Biko provided expert technical help. The authors thank K.V. Toyka for continuous support. The study was supported by research funds of the University of Würzburg.

\section{References}

Abdulla FA, Smith PA (1998). Axotomy reduces the effect of analgesic opioids yet increases the effect of nociceptin on dorsal root ganglion neurons. J Neurosci 18:9685-9694.

Andoh T, Itoh M, Kuraishi Y (1997). Nociceptin gene expression in rat dorsal root ganglia induced by peripheral inflammation. Neuroreport 8:2793-2796.

Arjomand J, Cole S, Evans CJ (2002). Novel orphanin FQ/nociceptin transcripts are expressed in human immune cells. J Neuroimmunol 130:100-108.

Bertorelli R, Bastia E, Citterio F, Corradini L, Forlani A, Ongini $E$ (2002). Lack of the nociceptin receptor does not affect acute or chronic nociception in mice. Peptides 23:15891596.
Briscini L, Corradini L, Ongini E, Bertorelli R (2002). Up-regulation of ORL-1 receptors in spinal tissue of allodynic rats after sciatic nerve injury. Eur J Pharmacol 447:59-65.

Calo' G, Guerrini R, Rizzi A, Salvadori S, Regoli D (2000). Pharmacology of nociceptin and its receptor: a novel therapeutic target. Br J Pharmacol 129:1261-1283.

Carpenter KJ, Vithlani M, Dickenson AH (2000). Unaltered peripheral excitatory actions of nociceptin contrast with enhanced spinal inhibitory effects after carrageenan inflammation: an electrophysiological study in the rat. Pain 85: 433-441.

Courteix C, Coudore-Civiale MA, Privat AM, Pelissier T, Eschalier A, Fialip J (2004). Evidence for an exclusive antinociceptive effect of nociceptin/orphanin FQ, an endogenous ligand for the ORL1 receptor, in two animal models of neuropathic pain. Pain 110:236-245.

Dong XW, Williams PA, Jia YP, Priestley T (2002). Activation of spinal ORL-1 receptors prevents acute cutaneous neurogenic inflammation: role of nociceptin-induced suppression of primary afferent depolarization. Pain 96:309-318.

Doya H, Ohtori S, Fujitani M, Saito T, Hata K, Ino H, Takahashi K, Moriya H, Yamashita T (2005). c-Jun N-terminal kinase activation in dorsal root ganglion contributes to pain hypersensitivity. Biochem Biophys Res Commun 16:132-138.

Dubner R, Ruda MA (1992). Activity-dependent neuronal plasticity following tissue injury and inflammation. Trends Neurosci 15:96-103.

Fiset ME, Gilbert C, Poubelle PE, Pouliot M (2003). Human neutrophils as a source of nociceptin: a novel link between pain and inflammation. Biochemistry 42:10498-10505.

Fukuoka T, Kondo E, Dai Y, Hashimoto N, Noguchi K (2001). Brain-derived neurotrophic factor increases in the uninjured dorsal root ganglion neurons in selective spinal nerve ligation model. J Neurosci 21:4891-4900.

Gabriel A, Pietruck C, Meuser T, Sharma M, Pierce Palmer P, Grond S (2004). Regulation of spinal nociceptin expression by neuropathic pain. Anaesthesist 53:621-628.

Hai T, Hartman MG (2001). The molecular biology and nomenclature of the activating transcription factor/cAMP responsive element binding family of transcription factors: activating transcription factor proteins and homeostasis. Gene 273:1-11.

Hao JX, Xu IS, Wiesenfeld-Hallin Z, Xu XJ (1998). Antihyperalgesic and anti-allodynic effects of intrathecal nociceptin/orphanin $\mathrm{FQ}$ in rats after spinal cord injury, peripheral nerve injury and inflammation. Pain 76:385-393.

Harrison LM, Grandy DK (2000). Opiate modulating properties of nociceptin/orphanin FQ. Peptides 21:151-172.

Hawes BE, Graziano MP, Lambert DG (2000). Cellular actions of nociceptin: transduction mechanisms. Peptides 21:961967.

Heinricher MM (2003). Orphanin FQ/nociceptin: from neural circuitry to behavior. Life Sci 73:813-822.

Henderson G, McKnight AT (1997). The orphan opioid receptor and its endogenous ligand-nociceptin/orphanin FQ. Trends Pharmacol Sci 18:293-300.

Itoh M, Takasaki I, Andoh T, Nojima H, Tominaga M, Kuraishi $Y$ (2001). Induction by carrageenan inflammation of prepronociceptin mRNA in VR1-immunoreactive neurons in rat dorsal root ganglia. Neurosci Res 40:227-233.

Janson W, Stein C (2003). Peripheral opioid analgesia. Curr Pharm Biotechnol 4:270-274. 
Jia Y, Linden DR, Serie JR, Seybold VS (1998). Nociceptin/ orphanin FQ binding increases in superficial laminae of the rat spinal cord during persistent peripheral inflammation. Neurosci Lett 250:21-24.

Koltzenburg M, Wall PD, McMahon SB (1999). Does the right side know what the left is doing? Trends Neurosci 22: 122-127.

Lindenlaub T, Sommer C (2000). Partial sciatic nerve transection as a model of neuropathic pain: a qualitative and quantitative neuropathological study. Pain 89:97-106.

MacArthur L, Ren K, Pfaffenroth E, Franklin E, Ruda MA (1999). Descending modulation of opioid-containing nociceptive neurons in rats with peripheral inflammation and hyperalgesia. Neuroscience 88:499-506.

Meunier JC, Mollereau C, Toll L, Suaudeau C, Moisand C, Alvinerie P, Butour JL, Guillemot JC, Ferrara P, Monsarrat B, Mazarguil H, Vassart G, Parmentier M, Costentin J (1995). Isolation and structure of the endogenous agonist of opioid receptor-like ORL1 receptor. Nature 377:532-535.

Mika J, Li Y, Weihe E, Schafer MK (2003). Relationship of pronociceptin/orphanin $\mathrm{FQ}$ and the nociceptin receptor ORL1 with substance $\mathrm{P}$ and calcitonin gene-related peptide expression in dorsal root ganglion of the rat. Neurosci Lett 348: 190-194.

Mogil JS, Pasternak GW (2001). The molecular and behavioral pharmacology of the orphanin $\mathrm{FQ}$ /nociceptin peptide and receptor family. Pharmacol Rev 53:381-415.

Monteillet-Agius G, Fein J, Anton B, Evans CJ (1998). ORL-1 and mu opioid receptor antisera label different fibers in areas involved in pain processing. J Comp Neurol 399:373-383.

Nakano H, Minami T, Abe K, Arai T, Tokumura M, Ibii N, OkudaAshitaka E, Mori H, Ito S (2000). Effect of intrathecal nocistatin on the formalin-induced pain in mice versus that of nociceptin/orphanin FQ. J Pharmacol Exp Ther 292:331-336.

Pettersson LM, Sundler F, Danielsen N (2002). Expression of orphanin $\mathrm{FQ} /$ nociceptin and its receptor in rat peripheral ganglia and spinal cord. Brain Res 945:266-275.

Reinscheid RK, Nothacker HP, Bourson A, Ardati A, Henningsen RA, Bunzow JR, Grandy DK, Langen H, Monsma FJ Jr, Civelli O (1995). Orphanin FQ: a neuropeptide that activates an opioidlike G protein-coupled receptor. Science 270: 792-794.

Rosen A, Lundeberg T, Bytner B, Nylander I (2000). Central changes in nociceptin dynorphin B and Met-enkephalin-ArgPhe in different models of nociception. Brain Res 857:212-218.
Schäfers M, Geis C, Svensson Cl, Luo ZD, Sommer C (2003). Selective increase of tumour necrosis factor-alpha in injured and spared myelinated primary afferents after chronic constrictive injury of rat sciatic nerve. Eur J Neurosci 17: 791-804.

Sommer C (2004). Serotonin in pain and analgesia: actions in the periphery. Mol Neurobiol 30:117-125.

Stein C, Millan MJ, Herz A (1988). Unilateral inflammation of the hindpaw in rats as a model of prolonged noxious stimulation: alterations in behavior and nociceptive thresholds. Pharmacol Biochem Behav 31:445-451.

Truong W, Cheng C, Xu QG, Li XQ, Zochodne DW (2003). Mu opioid receptors and analgesia at the site of a peripheral nerve injury. Ann Neurol 53:366-375.

Tsujino H, Kondo E, Fukuoka T, Dai Y, Tokunaga A, Miki K, Yonenobu K, Ochi T, Noguchi K (2000). Activating transcription factor 3 (ATF3) induction by axotomy in sensory and motoneurons: a novel neuronal marker of nerve injury. Mol Cell Neurosci 15:170-182.

Xu IS, Grass S, Calo G, Guerrini R, Wiesenfeld-Hallin Z, Xu XJ (2002). Intrathecal [Nphe1]nociceptin(1-13)NH2 selectively reduces the spinal inhibitory effect of nociceptin. Life Sci 70:1151-1157.

Xu IS, Grass S, Wiesenfeld-Hallin Z, Xu XJ (1999). Effects of intrathecal orphanin $F Q$ on a flexor reflex in the rat after inflammation or peripheral nerve section. Eur $\mathrm{J}$ Pharmacol 370:17-22.

Yamamoto T, Nozaki-Taguchi N, Kimura S (1997a). Effects of intrathecally administered nociceptin, an opioid receptorlike1 (ORL1) receptor agonist, on the thermal hyperalgesia induced by unilateral constriction injury to the sciatic nerve in the rat. Neurosci Lett 224:107-110.

Yamamoto T, Nozaki-Taguchi N, Kimura S (1997b). Analgesic effect of intrathecally administered nociceptin, an opioid receptor-like1 receptor agonist, in the rat formalin test. Neuroscience 81:249-254.

Yamamoto T, Nozaki-Taguchi N, Kimura S (1997c). Effects of intrathecally administered nociceptin, an opioid receptorlike1 (ORL1) receptor agonist, on the thermal hyperalgesia induced by carageenan injection into the rat paw. Brain Res 754:329-332.

Zöllner C, Shaqura MA, Bopaiah CP, Mousa S, Stein C, Schäfer M (2003). Painful inflammation-induced increase in mu-opioid receptor binding and G-protein coupling in primary afferent neurons. Mol Pharmacol 64:202-210. 